\title{
Narrativas de professoras sobre o TDAH: um estudo de caso coletivo
}

\author{
Narrativas de professoras sobre TDAH \\ Lílian Marx Flor Landskron \\ Tania Mara Sperb
}

\begin{abstract}
Resumo
O Transtorno de Déficit de Atenção e Hiperatividade (TDAH), considerado o transtorno de desenvolvimento infantil mais diagnosticado na atualidade, apresenta-se como tema freqüente e controverso na sociedade e grande desafio nas escolas. Os professores enfrentam situações que fogem às suas expectativas e buscam organizar o entendimento a partir de discursos discrepantes. Os valores e significados que subjazem as concepções sobre o TDHA se refletem no modo como as pessoas manejam a situação. Este estudo investigou a percepção de professores sobre o TDAH e salientou a complexidade do fenômeno ao abordar a diversidade de influências que o envolve. Utilizando o método da entrevista narrativa, foram analisadas histórias de nove professoras sobre uma experiência com um aluno diagnosticado. Os resultados indicam que a percepção das professoras sobre o transtorno é individualizante, patologizante, e o conhecimento, inconsistente. Os dados sugerem que este tema deve ser debatido em maior profundidade pela sociedade.

Palavras-chave: entrevista narrativa; professores; percepções; TDAH.
\end{abstract}

\section{Teacher's narratives about ADHD: a collective case study}

\begin{abstract}
Attention-Deficit Hyperactivity Disorder (ADHD), considered as the most commonly diagnosed behavioral disorder of childhood nowadays, is a frequent and controversial theme in society in general and also a great challenge for schools. Teachers have to deal with unexpected circumstances they are not prepared for and to manipulate discrepant discourses to organize their understanding of the situation. Furthermore, values and meanings underlying conceptions about ADHD influence the manner people deal with the situation. The present study investigated teachers' perception about ADHD and highlighted the complexity of the phenomenon when approaching the diversity of influences that involves it. Nine teachers' stories about their experiences with students diagnosed with ADHD were analyzed using the method of narrative interview. Results indicate that teachers' perception about the disorder is individualized, seen as pathologic, and their knowledge about the disorder is inconsistent. The data suggest that this theme should be deeper discussed by the society.
\end{abstract}

Keywords: interviews; teachers; perception; ADHD (Attention Dificit Disorder with Hyperactivity).

\section{Narraciones de profesoras sobre el TDAH: un estudio de caso colectivo}

\begin{abstract}
Resumen
El trastorno de Déficit de atención e hiperactividad (TDAH), actualmente considerado el trastorno de desarrollo infantil más diagnosticado, se presenta como un tema frecuente y controvertido en la sociedad, y un gran desafío en las escuelas. Los profesores enfrentan situaciones que no esperan y buscan entender sobre el asunto a partir de los discursos discrepantes que existen. Los valores y significados que sustentan las concepciones sobre el TDAH se reflejan en la forma en como las personas conducen la situación. Este estudio investigó la percepción de profesores sobre el TDAH y destacó la complejidad del fenómeno al abordar la diversidad de influencias que lo envuelven. Utilizando el método de la entrevista narrativa, fueron analizadas las historias de nueve profesoras sobre una experiencia con un alumno diagnosticado. Los resultados indican que la percepción de las profesoras sobre el trastorno es de carácter individual e patológico, así como el conocimiento es inconsciente. Los datos sugieren que este tema debe ser debatido con una mayor profundidad por la sociedad.

Palabras clave: entrevista narrativa; profesores; percepciones; TDAH.
\end{abstract}


O Transtorno de Déficit de Atenção e Hiperatividade (TDAH) vem, nas últimas décadas, tomando proporções cada vez maiores. Ele tem sido considerado o transtorno neurocomportamental mais comum da infância e a condição de doença crônica de maior prevalência na idade escolar (American Academy of Pediatrics, 2000). Gerou textos científicos, livros, artigos de jornal e apresentações regulares em convenções anuais e diversas associações de apoio aos pais no mundo todo. Segundo Davison (2001), nos Estados Unidos o diagnóstico tornou-se fenômeno nacional. A autora revela ter encontrado salas de aula com mais de $40 \%$ de alunos usando psicoestimulantes para o TDAH e ressalta dados da Drug Enforcement Administration - DEA que indicam aumento na produção e no uso de metilfenidato (psicoestimulante considerado como primeira escolha no tratamento de TDAH), de 1990 até 2001, na ordem de $600 \%$.

Diante deste quadro, vozes têm se levantado contra a idéia de se congregar em um transtorno único, diversos transtornos de atenção e motricidade com diferentes causas e implicações (Cruz, 2005; Fernàndez, 2005; Janin, 2000). Questiona-se a forma simplista e reducionista com que são pensadas as problemáticas psicopatológicas e o seu tratamento. Argumenta-se que o TDAH é apenas um rótulo que fornece conforto ante uma situação de pânico moral dos cuidadores das crianças, atropelados pelo crescimento da indisciplina e da indústria farmacêutica (Box, 1975/1981). A forma com que são realizados os diagnósticos, baseados em interpretações subjetivas de pais e professores sobre os comportamentos das crianças também é questionada (Davidson, 2001), assim como também se levanta a preocupação com os possíveis efeitos colaterais e as conseqüências orgânicas e psicológicas da dependência de medicação em idade precoce. Finalmente, denuncia-se a existência de interesses econômicos e políticos por trás dos diagnósticos (Moysés \& Collares, 1992).

Em meio a essa polêmica, pais, crianças $\mathrm{e}$ professores convivem com a questão de forma concreta no seu dia-a-dia. O comportamento inquieto e/ou desatento das crianças produz desconforto nos mais variados contextos, mas é, nas escolas onde se requer doses consideráveis de concentração e atenção, que o transtorno aparece de forma mais intensa (Barkley \& Pfiffner, 2002).

Utilizando a metodologia qualitativa de estudo de caso coletivo (Stake, 1994), este estudo buscou investigar como os professores percebem o TDAH e como vivenciam o trabalho com crianças que apresentam características típicas do transtorno. Para responder a essas questões, nove professoras das séries iniciais foram solicitadas a narrar uma experiência com um aluno diagnosticado como TDAH. O estudo utilizou como instrumento, a entrevista narrativa, proposta por Schuetze nos anos 70 e desenvolvida por Bauer (1996) e Bauer e Jovchelovitch (1999). As narrativas produzidas pelas professoras entrevistadas foram analisadas de modo a identificar os temas que emergiam de suas histórias e verificar como esses temas se articulavam na construção de uma narrativa pessoal sobre o TDAH.

A escolha da entrevista narrativa como instrumento metodológico fundamentou-se em dois princípios: a premissa de que as pesquisas deveriam abrir espaço para ouvir a voz do professor 
(Goodson, 1995) e a propriedade da teoria das narrativas de abrir novo horizonte para as investigações interpretativas ao revelar as intersecções entre aspectos sociais, culturais, pessoais e políticos (Riessman, 1993). Com sua estrutura maleável, a narrativa permite ao pesquisador investigar "a qualidade de abertura presente na mente discursiva e o descobrimento das formas multifacetadas de discursos culturais em que elas se realizam" (Brockmeier \& Harré, 2003, p. 534). Essa perspectiva vem sendo explorada de uma forma mais expressiva pela pesquisa científica nas últimas décadas, quando foram elaborados diferentes modelos de análise de entrevistas para pesquisas qualitativas.

\section{Interpretações biológica e sociológica do fenômeno}

As dificuldades acadêmicas e comportamentais são motivo de estudo há muitos anos, afirmam Moysés e Collares (1992), mas, a partir do final do século XIX, pesquisadores concentraram a busca das causas das dificuldades no funcionamento orgânico dos indivíduos, biologizando as questões educacionais. De acordo com Searigth e McLaren (1998), em 1937 Bradley descreveu uma síndrome de hiperatividade, a qual incluía desatenção, memória fraca e falta de inibição e teria como causa, uma leve lesão no Sistema Nervoso Central. Exames neurológicos indicaram que o quadro não era produto de lesão, mas de uma disfunção em determinada região cerebral. Assim, estruturou-se o conceito disfunção cerebral mínima (DCM), cujas manifestações teriam repercussão no comportamento e/ou na cognição do portador, porém não afetariam a inteligência e não indicariam alterações significativas nos exames físicos, neurológicos e laboratoriais (Moysés \& Collares, 1992).

Em 1980, segundo Searight e McLaren (1998), o Manual Diagnóstico e Estatístico de Transtornos Mentais da Academia Americana de Psiquiatria, o então DSM III, descreveu uma síndrome denominada Attention Deficit Disorders que incluía a hiperatividade como uma de suas características. Em 1987, a revisão do DSM III utilizou o termo Attention-Deficit Hyperactivity Disorder (ADHD) para denominar o transtorno, o qual foi subdividido em 1994 pelo então DSM IV em três subtipos: o TDAH com predomínio de sintomas de desatenção, o TDAH com predomínio de sintomas de hiperatividade/impulsividade e $\quad$ o $T D A H$ combinado. Os sintomas deste transtorno abrangem três categorias: desatenção (dificuldade para sustentar a atenção por períodos prolongados, seguir instruções, completar as lições e organizar tarefas; tendência a perder objetos, esquecer compromissos e distrair-se com estímulos externos); hiperatividade (agitação motora, inquietude e tendência a falar excessivamente); e impulsividade (dificuldade de aguardar sua vez e tendência de interromper os outros ou intrometer-se em assuntos alheios). Para inabilidades acadêmicas específicas como leitura, expressão escrita ou matemática, o DSM IV reservou o termo Transtornos de Aprendizagem.

Barkley (2000/2002) localiza as causas do TDAH no desenvolvimento anormal do cérebro, produzido por fatores genéticos, ambientais (como exposição do feto ao álcool e tabaco) e sociais, sendo que os primeiros prevaleceriam sobre os demais. Fatores sociais, segundo o autor, podem 
prognosticar a gravidade do quadro ou a presença de comportamentos mais agressivos ou desafiadores.

Biederman (2005) considera o TDAH um enorme peso para a sociedade em termos de custos financeiros, estresse familiar e problemas de desempenho. Segundo o autor, os sintomas prejudicam o funcionamento acadêmico, social e ocupacional do indivíduo acometido e estão associados a um aumento de risco para o fumo e o abuso de substâncias. Especialistas advertem que pessoas com TDAH apresentam dificuldade para aderir às leis e regras sociais e estão mais sujeitas a acidentes e situações indesejáveis, como gravidez precoce, doenças sexualmente transmissíveis, multas de trânsito, conflitos matrimoniais e depressão (International Consensus Statement on ADHD, 2002).

A visão médica, portanto, define o problema em termos biológicos e está voltada para o tratamento dirigido a um indivíduo que apresenta uma deficiência. O procedimento recomendado consiste em avaliação por pediatra para descartar causas médicas, diagnóstico baseado nos critérios do DSM-IV e tratamento combinando medicamentos e programas educacionais ou psicoterápicos para ajudar o portador a desenvolver estratégias compensatórias (Barkley, 2000/2002).

Vários especialistas da área da saúde que trabalham com problemas comportamentais e da aprendizagem, porém, preocupam-se com a ênfase excessiva dada aos aspectos biológicos e advertem que o pensamento que aceita como válidos os argumentos individualizantes e patologizantes desconsidera aspectos contextuais e intra-psíquicos (Cruz, 2005; Fernández, 2005; Janin, 2000).
Baseada em estudos realizados na Investigación S.P.P.A. (Situación Persona Prestando Atención), Fernández (2005) explica que o atender foi tradicionalmente avaliado na escola com base na capacidade do aluno de reproduzir o objeto de conhecimento. Esse modo de entender o atender está associado a uma representação de atenção focalizada e obediente. Na concepção de De-Nardin e Sordi (2007), é esta atenção, entendida como uma função cerebral mensurável e valorizada por manter a seletividade e a constância, que está subjacente à concepção do TDAH. As autoras pontuam que pesquisas de autores como Crary (2000), Corea (2005), Kastrup (2004) e Lewcowicz (2005) indicam que as formas de atentar e de se concentrar das pessoas não são determinadas pela biologia, mas mediadas por vivências contextualizadas histórica e culturalmente. Até mesmo o próprio interesse pelo assunto tem um caráter histórico. Segundo Crary (2000), foi somente após a revolução industrial, quando se tornou um aspecto crucial para as novas formas de produção, que a atenção passou a ser investigada experimentalmente como um tópico privilegiado.

Para Kastrup (2004), a sociedade contemporânea conserva uma concepção reducionista da cognição, tratando-a como mera capacidade de solução de problemas, e investe maciçamente na atenção focalizada devido à sua participação no controle do comportamento e na realização de tarefas. Segundo a autora, a falha na captação e busca de informações são consideradas evidências de problemas de desatenção e os sujeitos são situados em um quadro individual e patológico. Kastrup, salientam DeNardin e Sordi (2007), propõe uma ampliação do conceito de cognição, introduzindo uma natureza 
inventiva que possibilita ao sujeito inventar a si e ao mundo. Esse tipo de cognição estaria relacionado a dois modos distintos e complementares de atenção, o recognitivo e o inventivo. $\mathrm{O}$ modo recognitivo estaria relacionado ao reconhecimento dos objetos e à sua atuação no desempenho das tarefas diárias, enquanto o inventivo seria caracterizado pela capacidade do sujeito encontrar-se com o inesperado e problematizar. A modalidade inventiva implicaria necessariamente em uma concentração, entendida como uma possibilidade de ir além da capacidade de executar tarefas: haveria uma inibição do foco, embora o sujeito continuasse conectado à experiência, e se abriria a possibilidade de deixar-se afetar pelo objeto. A forma inventiva de aprender supõe uma capacidade de transmitir continuamente entre atenção e desatenção.

Lewcowicz (2005) e Corea (2005) apresentam uma linha de raciocínio diferenciada sobre a desconcentração dos alunos atuais denunciada pelos professores. Partindo de análises históricas, Lewcowicz (2005) entende que não existe uma natureza humana dada; as subjetividades são produzidas mediante distintas práticas. As queixas dos professores sobre as dificuldades de os alunos aprenderem a ler, a escrever e a se comportarem de forma disciplinada e participativa em classe seria, na realidade, fruto de um desajuste subjetivo, um descompasso entre a forma de pensar e de se relacionar com a informação entre o aluno suposto pelo docente e o aluno real. O professor supõe relacionar-se com um aluno cuja subjetividade teria sido construída em torno da lei e das demandas capitalistas por produção, própria de uma época em que ainda vigorava e imperava a megainstituição Estado-Nação, mas depara-se com um aluno constituído em uma lógica mercantil, completamente diferente da institucional: a lógica da era da informática, da velocidade e da fluidez. O pensamento da criança da era da telemática, explica Corea (2005), baseando-se em suas investigações realizadas no Estúdio LWZ (organização que concentra atividades diversas, como cursos, oficinas, assessorias, investigações, publicações e intervenções), tem base perceptiva, diferente do pensamento da era institucional. É não elaborativo ou associativo, e não requer a consciência, a interpretação e a representação. Os dispositivos de informação requerem do usuário eficaz uma velocidade considerável e uma hiperconexão a diversas interfaces desarticuladas entre si. $\mathrm{O}$ pensamento, na verdade, retarda a reação. $\mathrm{O}$ indivíduo não consegue explicar a outra pessoa um dado procedimento, porque a sua relação com a informação é puramente mecânica. Nas operações próprias do entorno informacional cai a possibilidade de transferir, destituindo-se a subjetividade pedagógica. O discurso pedagógico requer interioridade e concentração. As diversas e velozes informações recebidas pelo indivíduo não chegam a ser interiorizadas e estão desprovidas de um sentido instituído ou o sentido está instituído de forma lábil. Segundo Corea (2005), a excessiva solicitação do meio, hipersaturada de estímulos em todos os níveis, leva a criança a responder defensivamente com a desconexão e a dispersão. A hiperatividade seria, pois, um efeito da relação contemporânea com os entornos informacionais. E essa característica não seria exclusiva à criança com TDAH, mas atingiria a maioria das crianças atuais. A questão do TDAH, segundo a autora, não deveria ser colocada em termos de uma conduta sintomática 
a ser tratada, mas de um modo em que se configura a subjetividade contemporânea.

Em meio aos discursos médico (Barkley, 2000/2002) e psicossocial (Corea, 2005; Kastrup, 2004), os professores buscam organizar o entendimento e construir um significado pessoal para as suas experiências (Lawrence \& Valsiner, 2003). Baseados nos pressupostos vygotskyanos de que o pensamento é mediado por produtos culturais (como a linguagem e outros sistemas simbólicos) e que o mundo psicológico do indivíduo é construído de forma ativa e subjetiva na sua relação e confronto com o mundo psicológico dos outros e com o meio ambiente, Lawrence, Dodds e Valsiner, (2004) propõem que toda vez que o indivíduo se depara com uma situação nova, aciona-se o sistema próprio de busca de sentido, cuja finalidade é auxiliá-lo a compreender seu papel no contexto a partir de suas experiências de vida e expectativas.

Um dos instrumentos utilizados pelo indivíduo para organizar a experiência e construir sentido para os eventos e as ações em sua vida é a elaboração de narrativas pessoais (Riessman, 1993). Segundo Brockmeier e Harré (2003), as narrativas se configuram em um conjunto de instruções e normas para realizar diversas práticas comunicativas, como ordenar, dar sentido às experiências, promover conhecimento, apresentar desculpas e justificativas. Elas operam como um instrumento da mente, afirma Bruner (1991). Não somente representam, mas efetivamente constroem e constituem a realidade do sujeito. Ao narrar a sua experiência para colegas, amigos ou supervisores, os professores procuram organizar o conhecimento e se posicionar na prática profissional.
O objetivo do presente estudo foi investigar como os professores brasileiros, residentes em cidades distantes das grandes metrópoles, percebem e vivenciam a situação de ter um aluno com TDAH em suas salas de aula e como organizam os discursos médico e psicossocial e os elementos da sua realidade para construir uma narrativa pessoal sobre a experiência.

\section{Método}

\section{Participantes}

Participaram da pesquisa nove professoras das séries iniciais do ensino fundamental. As escolas estão localizadas em uma região do interior do Rio Grande do Sul, de origem germânica, que possui aproximadamente 100.000 habitantes. Dentre as participantes, quatro lecionavam em escolas particulares e cinco pertenciam à rede estadual de ensino. As participantes tinham, em média, 39,3 anos de idade e 19,2 anos de experiência com alunos do ensino fundamental nas séries iniciais. Foram utilizados os seguintes critérios de inclusão: praticar a unidocência (serem responsáveis por todas as áreas do conhecimento, permanecendo o turno inteiro com a turma de alunos); ter lecionado a alguma criança diagnosticada como portadora de TDAH.

\section{Material e Instrumentos}

Foram utilizados a ficha de dados sociodemográficos (nome, idade, nacionalidade, estado civil, formação, ocupação atual, número de ano lecionando, orientações recebidas sobre o TDAH), o gravador digital e a entrevista narrativa. 
A entrevista era constituída por uma questão única, aberta, lançada após um período de conversa informal para estimular um clima de confiança e descontração: "Gostaria que você contasse uma experiência sua com um aluno que possuía diagnóstico de TDAH'. O instrumento e os procedimentos foram analisados previamente por meio de estudo piloto. A entrevista tinha como objetivo propiciar a fala livre, espontânea e sem direcionamentos. À pesquisadora era facultado, ao término da narração espontânea, incentivar a continuação da fala com questões do tipo: "E aí, o que aconteceu?". Após o término da narrativa, o gravador era desligado e aspectos relevantes podiam ser esclarecidos.

\section{Procedimento}

O contato com as participantes foi realizado por meio dos Serviços de Orientação e Supervisão (SOE) das instituições, aos quais foi solicitado um levantamento de casos de alunos diagnosticados de TDAH. Os professores destas crianças foram identificados, sorteados e convidados a participar da pesquisa. Todas as entrevistas foram realizadas nas escolas. Cada participante foi solicitada a preencher a ficha com os dados sociodemográficos e, após, convidada a participar de uma entrevista narrativa, gravada em videocassete. As entrevistas foram transcritas integralmente e analisadas segundo a proposta de Bauer (1996) e Bauer e Jovchelovitch (1999). Foram registradas as observações da pesquisadora durante a entrevista com as participantes (as expectativas das participantes ao conceder a entrevista, por meio das ênfases e justificativas apresentadas na narrativa e o tipo de indagações e observações realizadas informalmente após a gravação) e no contato com o SOE (forma de encaminhamentos, resposta dos pais ao encaminhamento, número de casos diagnosticados, número de alunos da escola, extensão da educação oferecida na instituição).

Para a análise de cada narrativa, foram separados em quadros o material indexical (referências concretas de quem fez o quê, quando, onde e porque) e as descrições generalizadas (material mais descritivo e argumentativo que expressava sentimentos, valores, opiniões, juízos, sabedoria popular, tradições, cultura, etc.). Foram realizadas descrição do contexto escolar, elaboração de uma síntese para cada narrativa, identificação das expectativas da narradora ao conceder a entrevista e explicitação das questões emergentes (personagens apresentados, eventos e suas implicações, problemas encontrados, soluções apontadas e resistências percebidas). Finalmente, foi elaborada uma trajetória coletiva de todos os casos para salientar as situações comuns e as idiossincrasias.

\section{Resultados e Discussão}

Os temas identificados nas narrativas das professoras foram organizados em três tópicos principais: descrição das dificuldades enfrentadas pelas professoras com relação ao comportamento hiper/hipoativo e/ou desatento e ao desempenho insuficiente dos alunos com TDAH, explicação das participantes para o comportamento destas crianças (emergente nas narrativas e relacionada no quadro declarações generalizadas da análise dos dados) e apresentação das estratégias de intervenção. 
Dificuldades enfrentadas pelas professoras com relação ao comportamento hiper/hipoativo e/ou desatento e ao desempenho insuficiente dos alunos com TDAH

Todos os casos narrados neste estudo envolveram meninos, sendo que sete dos nove alunos descritos apresentavam sintomas de hiperatividade. Esses resultados corroboram a literatura. Os estudos e a experiência clínica indicam que as meninas apresentam mais sintomas relativos ao TDAH com predomínio de desatenção e menos sintomas de conduta em comorbidade (Rohde \& Halpern, 2004). De acordo com Denckla (2005), os meninos se encontram mais sob o foco da sociedade e são mais encaminhados a tratamento médico.

As participantes demonstraram grande preocupação com os comportamentos agitados e com a dificuldade dos alunos para se concentrarem em tarefas rotineiras, o que sugere que a conformidade comportamental e o desempenho das crianças são questões muito valorizadas. Aparece uma pressão social sobre a produção (Fontoura, 1995) com muita nitidez nas palavras da professora F.: "Gente, não se entendia [o caderno de F1]. Não fazia, não tinha nada, não tinha seqüência... Quem olhasse aquilo ía pensar: 'Meu Deus! Que será que fazem naquela... naquela turma, naquela série, com aquela professora?" A maioria das descrições apontava para posturas de desleixo, desorganização e produção insuficiente, apesar de seis participantes explicitarem o potencial positivo dessas crianças para aprender. A noção de aprendizagem aparece muito vinculada à realização de tarefas. A criança que não produz é uma criança que não corresponde às expectativas e requer solução urgente. As narrativas das professoras referentes a seis casos, nos quais o medicamento foi adequadamente administrado, indicam que a medicação provocava mudanças no comportamento das crianças, deixando-as menos agitadas e mais concentradas. Tal mudança parece ter reduzido a ansiedade das professoras, como pode ser verificado na fala da professora D.: "Depois que ele começou a tomar Ritalina, ele... ele deu uma boa evoluída, ele consegue ficar quietinho, fazendo as tarefas dele, se concentra mais."

A característica emocional mais ressaltada das crianças foi vulnerabilidade à pressão por produtividade. Seis professoras narraram situações nas quais a criança reagia intempestivamente quando era forçada a produzir. As participantes mostravam-se preocupadas e inseguras quanto à sua atuação, como pôde ser observado pelo tom de surpresa e autocrítica transparente na fala da professora C.: "E, a partir dali, ele começou a t... a reagir, porque ele... ele se sentiu... eu... ao meu ver, ele se sentiu pressionado. Por mim. (...) E pelos pais, também, muita cobrança. (...) ele começou a mostrar (...) aquela... coisa que ele estava sendo pressionado pra fora." A presença de justificativas recorrentes nas narrativas sobre posicionamentos nas situações críticas sugere a presença de um conflito interno nas participantes entre assegurar o desempenho ou priorizar o desenvolvimento das capacidades individuais (Holly, 1995).

As narrativas das professoras demonstram que 0 lidar com um aluno que apresenta características de TDAH e sua família mobiliza sentimentos intensos, como irritação, impaciência, receio e cansaço. Sentimentos de perplexidade e perturbação indicam estranhamento e desconforto ante um 
comportamento não esperado, diferente do aluno ideal para o qual elas foram preparadas (Suplino, s.d.). A professora B. expressa: “... a classe dele, a cadeira dele nunca ficava no lugar (...) aquele caderno dele, às vezes, estava virado pra ele, às vezes estava pro lado (...) a mochila nunca estava do lado da cadeira dele, ela estava pelo meio do corredor..." A dificuldade de controlar o comportamento contrasta com a postura idealizada, que se coaduna ao sistema de ensino tradicional. $\mathrm{O}$ aluno que não corresponde às expectativas da escola tende a ser trabalhado para se ajustar, adaptar.

\section{Explicação para o comportamento diferenciado das crianças com TDAH}

Os dados indicam que o conhecimento das participantes sobre o TDAH estava praticamente restrito aos sintomas característicos do transtorno. Apesar de se referirem às dificuldades dos alunos como manifestações de um transtorno orgânico, somente uma professora descreveu o processo neuronal e as estratégias educativas recomendadas por especialistas. Uma das participantes aventou a possibilidade de haver influência da alimentação sobre o comportamento hiperativo. As demais referências a causas orgânicas restringiram-se a justificativas sobre a necessidade de medicação baseadas em recomendação médica e no efeito positivo verificado. Além disso, apesar de as referências serem orgânicas, as explicações para o comportamento desajustado eram, em geral, psicológicas, com alusões a conflitos familiares e dificuldade dos pais na imposição de limites. A ambivalência sobre a natureza do transtorno sugeriu que a concepção sobre o TDAH ainda estava em processo de construção. Imersas em um campo vivo de sugestões de significados, sentimentos e ações, as professoras pareciam procurar equacionar as idéias dominantes e contraditórias para construir uma versão pessoal sobre a experiência (Lawrence \& Valsiner, 2003), emprestando, misturando e remodelando diversos discursos culturais (Danforth \& Navarro, 2001).

É curioso notar que uma das professoras manifestou discordar do diagnóstico médico: “...eu não achava que fosse uma... hiperatividade. Prá mim foi uma grande surpresa quando veio o diagnóstico, né, de hiperatividade. (...) e o que acontecia com ele dentro da sala de aula, a parte, tudo era só agressividade”. Ao posicionar-se de forma crítica ante o diagnóstico, a professora demonstrou reconhecer o próprio conhecimento e intuição e superar o receio de questionar o saber médico. Esse posicionamento não é confortável na sociedade contemporânea, tendo-se em vista que procedimentos institucionais com o peso da cientificidade adquirem status que lhes confere credibilidade privilegiada (Schrag \& Divoky, 1975/1981). O diagnóstico do médico é tomado, normalmente, como inquestionável e suas orientações são recebidas como ordem, como pode ser verificado nas palavras da professora G.: "Ele necessita tomar o remédio. (...) que o doutor mandou... ela dá, né?", porém, Cruz (2005) ressalta que o poder médico não é monolítico, homogêneo e nem ahistórico. Existem fissuras por onde escapam situações que não são respondidas pela medicina, há opiniões divergentes dentro da própria instituição médica e o saber médico possui um caráter dinâmico, aberto ao contexto social e ao devenir histórico. De fato, as divergências entre os médicos 
fazem parte da realidade destes profissionais. Em um encontro internacional em Amsterdã, na Holanda, em 2003, Mattos declarou-se preocupado com o elevado número de crianças que chega aos serviços de saúde especializados utilizando medicação errada (Associação Brasileira do Déficit de Atenção, s.d.).

Algumas professoras acrescentaram comportamentos que não pertencem ao quadro do TDAH, demonstrando confusão e/ou falta de conhecimento sobre o transtorno, como pode ser verificado na descrição da professora F.: “... aí ele queria se justificar, ele começa a gritar, gritar, gritar, gritar, gritar! (...) ele começa a gritar e a falar alto, também coisas do outro colega e coisas que ele também faz, né?" Segundo o Consenso Brasileiro de Especialistas sobre Diagnóstico do TDAH em Adultos (s.d.), comportamentos de irritabilidade e temperamento explosivo são considerados sintomas independentes do quadro e aparecem somente em casos mais graves e/ou outros transtornos TDAH-símile ou comórbidos. Davison (2001) adverte que as incongruências na descrição da natureza do transtorno podem ajudar a explicar a tendência da sociedade a identificar precipitadamente comportamentos disruptivos como sintomas de TDAH.

\section{Apresentação das estratégias de intervenção}

Todas as professoras manifestaram a importância do trabalho conjunto com as famílias, tendo algumas incluído os profissionais que atendiam as crianças. A professora $H$. não mediu esforços para entrar em contato com a mãe de H1: "Eu disse: 'Ó, eu estou me colocando à disposição dessa mãe’. Porque eu sabia que ela morava em X, que ela só podia... por telefone ou no fim-desemana, quando ela viesse. Eu disse: 'Olha, ela pode vir na minha casa fim-de-semana...," Em geral, as professoras descreveram famílias esforçadas, presentes e comprometidas com o desenvolvimento pleno de seus filhos. Algumas professoras, porém, queixaram-se de que as famílias se mostravam resistentes para revelar informações sobre a saúde e intimidade do lar e para aceitar a sugestão da escola de aderir ao tratamento medicamentoso, descrevendo verdadeiras batalhas travadas nesse sentido. Este fato era relatado como evidência de falta de espírito de cooperação ou de consciência sobre a necessidade da medicação. Apesar disso, algumas participantes demonstraram empatia em relação às dificuldades da família, parecendo compartilhar do receio de medicar crianças em fase de desenvolvimento. A professora B., por exemplo, apesar de disponibilizar-se a administrar o remédio quando solicitada, demonstra grande preocupação: “E o que pode acontecer com uma criança que toma Ritalina? Se uma mãe lê aquela bula, a mãe não dá pra uma criança! Né? É bem sério..."

É importante ressaltar que as professoras que não ficaram paralisadas à espera da medicação acabaram desenvolvendo intervenções importantes com a criança e com os demais alunos. Experientes, contando a maioria com mais de 18 anos de vivência em sala de aula, as professoras usavam a intuição e o conhecimento adquirido para acolher e fortalecer a auto-estima do aluno, conquistando seu afeto e confiança, evitando punições excessivas, buscando atividades gratificantes e oferecendo atenção personalizada. Elaboravam, ainda, medidas educativas, como conscientizar a criança sobre as 
conseqüências dos seus atos, orientar quanto à (in)adequação de algumas atividades, cobrar combinações com firmeza e treinar habilidades compensatórias. Mesmo sem contar com a medicação administrada conforme a indicação médica, a professora $\mathrm{E}$ ressalta que alcançou resultados significativos com $\mathrm{E} 1$, assegurando a motivação e a participação ativa do aluno nas atividades acadêmicas e sociais. “...agora ele está entrando mais de acordo com...com a turma, assim. Ele participa da aula, ele gosta de participar na aula. Participa bastante (...) Eu acho que ele se sente bem melhor, sabe? (...) ele gosta de vir para a escola”. É curioso notar que essas atitudes, contudo, não eram apropriadas pelas participantes como parte integrante do tratamento. Elas foram apresentadas com uma conotação de estratégias alternativas, paliativas, implantadas enquanto as famílias não se comprometiam com o tratamento medicamentoso, a solução considerada eficaz.

Algumas professoras também mencionaram esforços para trabalhar a inclusão da criança na turma e diminuir o peso do rótulo. A professora $\mathrm{E}$. comentou: “Daí, nesse dia, eu conversei sobre o E1 com eles, com todos eles. (...) Eles estão tentando me ajudar, porque eu acho que nós não podemos excluir o E1”. É interessante notar que as professoras também pareciam não se dar conta da importância deste trabalho. Preocupadas com o tempo e esforços despendidos desigualmente entre os alunos, as participantes não pareciam notar que a presença de uma criança com necessidades especiais na sala de aula, como bem salientam Marchesi e Martín (1995), pode ser uma oportunidade ímpar para trabalhar questões de cidadania.

\section{Considerações Finais}

Embora não seja possível generalizar os resultados encontrados no presente estudo, tendo-se em vista as suas limitações em termos de números de participantes e o fato de estar circunscrito a apenas uma cidade brasileira, os mesmos sugerem a existência de uma percepção patologizante das dificuldades dos alunos, descritas em termos de deficiência. Quer indicando causas biológicas, quer ressaltando as influências psicossociais, as professoras situaram o problema individualmente, em crianças específicas com dificuldade para se adequarem aos padrões de comportamento de um modelo pré-concebido. Questões como o clima de anomia nas escolas atuais e a desmotivação generalizada dos demais alunos (Lewcowicz, 2005) não foram destacadas pelas participantes, que pareciam monopolizadas pelo sintoma individual. Quando se aborda, porém, o TDAH de uma forma mais ampla, contemplando cuidadosamente o contexto no qual se insere e sob diferentes enfoques (Barkley, 2000/2002; Box, 1981; Davison, 2001; Danforth \& Navarro, 2001; Denckla, 2005; Fernàndez, 2005; Kastrup, 2004; Moysés \& Collares, 1992; Searigth \& MaLaren, 1998), tornase notório que este é um tema complexo, que extrapola a questão biológica. $E$ isto leva a concordar com Fernàndez (2005), Cruz (2005) e tantos outros especialistas da área da saúde que trabalham tais crianças com TDAH (Consenso de Expertos Argentinos, 2005), que explicar o comportamento da criança unicamente a partir do aspecto individual é uma forma reducionista e linear de pensamento, pois não dá conta da 
multiplicidade de causas e efeitos. Medicar a criança que apresenta dificuldades de adaptação, sem refletir sobre as implicações do procedimento e considerar todos os fatores influentes, pode dissimular ou encobrir precipitadamente conflitivas individuais, sociais ou institucionais que deveriam ser identificadas e trabalhadas.

Tanto a interpretação biológica do transtorno como a interpretação sociológica, embora consistentemente fundamentadas, são visões parciais e acabam por menoscabar a ação do professor. Colocam-no em situação de espera por uma solução externa que extrapola a sua competência. A esperança fica depositada no medicamento, que vai adaptar o aluno à escola, ou nas instâncias superiores do sistema de ensino, que vão prover a escola de recursos materiais e pedagógicos para que esta se adapte à criança que se distingue do esperado. Algumas participantes, porém, demonstraram conseguir superar essas perspectivas lineares e relacionaram-se com o aluno como um indivíduo, sem transformá-lo em um problema a ser resolvido (Fernández, 2005). Utilizando afeto e sabedoria, aproximaram-se da criança, buscaram conhecer a sua forma de aprender e de se relacionar com o mundo e reforçaram a crença na sua capacidade. Com isso, alcançaram resultados altamente positivos como a motivação e a participação ativa do aluno nas atividades acadêmicas e sociais. A forma com que o professor lida com a situação é determinante tanto no desenvolvimento psicológico do aluno como no crescimento de toda a comunidade escolar e a sua participação no processo deve ser esclarecida e reforçada. Nas narrativas, as poucas alusões a questões importantes do fenômeno como as implicações do rótulo, o aumento do número de diagnósticos, a intolerância social à diferença, o descompasso entre as demandas socioculturais da vida contemporânea e o que é solicitado no contexto escolar, sugerem que o tema do TDAH requer a abertura de um espaço privilegiado de reflexão, discussão e compartilhamento de experiências.

\section{Referências}

American Academy of Pediatrics. (2000). Diagnosis and evaluation of the child with attentiondeficit/hyperactivity disorder. Pediatrics, 105 (5), 11581170 .

Associação Brasileira do Déficit de Atenção (s.d.). Afinal, temos direitos? Recuperado: 11 abr. 2007. Disponível:

http://www.tdah.org.br/reportagem02.php?id=14.

Barkley, R. A. (2002). Transtorno de déficit de atenção/hiperatividade (TDAH): Guia completo para pais, professores e profissionais da saúde (L. S. Roizman, trad.). Porto Alegre: Artmed. (Trabalho original publicado em 2000)

Barkley, R. A., \& Pfiffner, K. J. (2002). Rumo à escola com o pé direito: Administrando a educação de seu filho. Em R. A. Barkley (Org.), Transtorno de Déficit de Atenção/Hiperatividade (TDAH): Guia completo para pais, professores e profissionais da saúde (L. S. Roizman, trad.). Porto Alegre: Artmed. (Trabalho original publicado em 2000)

Bauer, M. (1996). The narrative interview: Comments on a technique for qualitative data collection. Recuperado: 25 jan. 2007.2 Disponível: 
http://www.lse.ac.uk/collections/methodologyInstitute/pd f/QualPapaers/Bauer-NARRAT1SS.pdf.

Bauer, M. W., \& Jovchelovitch, S. (1999). A questão da metodologia em pesquisa: texto, imagem e materiais sonoros. Manual de curso de extensão. Manuscrito não publicado, Pontifícia Universidade Católica de Porto Alegre, Grupo de Pesquisa em Ideologia, Comunicação e Representações Sociais.

Biederman, J. (2005). Attention deficit/hyperactivity disorder: A selective overview. Biological Psychiatry, 57(11), 1215-1220.

Box, S. (1981). Preface. Em P. Schrag \& D. Divoky (Orgs.), The myth of the hyperactive Child and other means of child control (pp.7-30). Middlesex: Penguin Books Ltd. (Trabalho original publicado em 1975)

Brockmeier, J., \& Harré, R. (2003). Narrativa: Problemas e promessas de um paradigma alternativo. Psicologia: Reflexão e crítica, 16(3), 525-535.

Bruner, J. (1991). The narrative construction of reality. Critical Inquiry, 18(1), 1-21.

Consenso Brasileiro de Especialistas sobre Diagnóstico do TDAH em Adultos (s.d.). Recuperado: 24 out. 2006. Disponível: http://www.tdah.org.br/consenso_final.pdf .

Consenso de Expertos del área de la salud sobre el llamado "Trastorno por Déficit de Atención con o sin Hiperactividad" (2005). Recuperado: 07 ago. 2006. Disponível: http://www.jorgegaraventa.com.ar/consenso.htm.

Corea, C. (2005). Los chicos-usuarios en la era de la información. Em C. Corea \& I. Lewcowicz (Orgs.), Pedagogía del aburrido: Escuelas destituídas, famílias perplejas (pp. 175-184). Buenos Aires: Paidós.
Crary, J. (2000). Suspensions of perception: Attention, spectacle and modern culture. London: MIT Press.

Cruz, J. G. (2005). ADD: Niños y jóvenes con “déficit atencional": desatentos o desatendidos? Manual do curso breve à distância Nuevos aportes de la psicopedagogía ante el cuestionado diagnóstico de ADD/ADHA (TDA/TDAH). Manuscrito não publicado, Escuela Psicopedagógica de Buenos Aires Espacio Psicopedagógico Brasileño.

Danforth, S., \& Navarro, V. (2001). Hyper talk: Sampling the social construction of ADHD in everyday language. Anthropology \& Education Quarterly, 32(2), 167-190.

Davison, J. (2001). Attention deficit/hyperactivity disorder: Perspectives of participants in the identification and treatment process. Journal of Educational Thought, 35(3), 227-247.

De-Nardin, M. H., \& Sordi, R. O. (2007). Um estudo sobre as formas de atenção na sala de aula e suas implicações para a aprendizagem. Psicologia \& Sociedade, 19(1), 99-106.

Denckla M. B. (2005). Niñas com TDAH. Recuperado: 25 jan. 2007.2 Disponível: http://www.deficitdeatencionperu.org/dencklacastellano. htm.

Fernández, A. (2005). La sociedad "hiperkinética" y "desatenta" medica lo que produce. Manual do curso breve à distância Nuevos aportes de la psicopedagogía ante el cuestionado diagnóstico de ADD/ADHA (TDA/TDAH). Manuscrito não publicado, Escuela Psicopedagógica de Buenos Aires Espacio Psicopedagógico Brasileño.

Fontoura, M. M. (1995). Fico ou vou-me embora? Em A. Nóvoa (Org.), Vidas de Professores (M. dos A. Caseiro 
\& M.F. Ferreira, trad.). (2 ${ }^{\mathrm{a}}$ ed., pp.171-177). Porto: Porto.

Goodson, I. F. (1995). Dar voz ao professor: As histórias de vida dos professores e o seu desenvolvimento profissional. Em A. Nóvoa (Org.), Vidas de Professores (M. dos A. Caseiro \& M. F. Ferreira, trad.). ( $2^{\text {a }}$ ed., pp.63-69). Porto: Porto.

Holly, M. L. (1995). Os professores e os contextos conceptuais de ensino. Em A. Nóvoa (Org.), Vidas de Professores (M. A. Caseiro \& M. F. Ferreira, trad.). (2 ed., pp.79-86). Porto: Porto.

International Consensus Statement on ADHD. (2002). International Consensus Statement on ADHD. Clinical Child and Family Psychology Review, 5(2), 89-111.

Janin, B. (2000). Síndrome de ADD? Recuperado: 23 jan. $2007 . \quad$ Disponível: http://www.geocities.com/ lerre/janin.html.

Kastrup, V. (2004). A aprendizagem da atenção na cognição inventiva. Psicologia \& Sociedade, 16(3), 7-16.

Lawrence, J. A, Dodds, A. E., \& Valsiner, J. (2004). The many faces of everyday life: Some challenges to the psychology. Culture \& Psychology, 10(4), 455-476.

Lawrence, J. A., \& Valsiner, J. (2003). Making personal sense: An account of basic internalization and externalization processes. Theory \& Psychology, 13(6), 723-752.

Lewkowicz, I. (2005). Escuela y ciudadanía. Em C. Corea \& I. Lewcowicz (Orgs.), Pedagogía del aburrido: Escuelas destituídas, famílias perplejas (pp. 19-40). Buenos Aires: Paidós.
Marchesi, A., \& Martín, E. (1995). Da terminologia do distúrbio às necessidades educacionais especiais. Em A. Nóvoa (Org.), Vidas de Professores (M. A. Caseiro \& M. F. Ferreira, trad.). (2 $\mathrm{a}$ ed., pp.171-177). Porto: Porto.

Moysés, M. A. A., \& Collares, C. A. L. (1992). A história não contada dos distúrbios de aprendizagem. Cadernos CEDES, 28, 31-47.

Riessman, C. K. (1993). Narrative Analysis. Em P. Atkinfon \& S. Dealmont (Orgs.), Qualitative research methods (Vol. 30). Newbury Park: Sage Publications.

Rohde, L. A., \& Halpern, R. (2004). Transtorno de déficit de atenção/hiperatividade: atualização. Jornal de Pediatria, 80(2), 61-70.

Schrag, P., \& Divoky, D. (1981). The myth of the hyperactive Child and other means of child control. Middlesex: Penguin Books Ltd. (Trabalho original publicado em 1975)

Searight, H. R., \& McLaren, A. L. (1998). AttentionDeficit Hyperactivity Disorder: The medicalization of misbehavior. Journal of Clinical Psychology in Medical Settings, 5(4), 467-495.

Stake, R. E. (1994). Case Studies. Em N. Denzin \& Y. Lincoln (Orgs.), Handbook of qualitative research (pp. 236-247). London: Sage.

Suplino, M. (s.d.). Inclusão escolar de alunos com autismo. Recuperado: 21 nov. 2006. Disponível: http://www.mj.gov.br/sedh/ ct/conade/Documentos/suplino.doc 
Recebido em: 21/05/2007

Revisado em: 02/01/2008

Aprovado em: 08/01/2008

Sobre as autoras:

Lílian Marx Flor Landskron (lilianland@ viavale.com.br) - Programa de Pós-Graduação em Psicologia da Universidade Federal do Rio Grande do Sul

Tania Mara Sperb - Programa de Pós-Graduação em Psicologia da Universidade Federal do Rio Grande do Sul

Endereço para correspondência:

Lílian Landskron

Henrique Kroth, 60

CEP $96825-240$

Santa Cruz do Sul - RS

Nota das autoras:

Trabalho derivado de Dissertação de Mestrado do Programa de Pós-Graduação em Psicologia da Universidade Federal do Rio Grande do Sul. 